\title{
SITUATIONAL SPEAKING DIFFICULTIES OF ENGLISH AS SECOND LANGUAGE LEARNERS IN THE PHILIPPINES
}

\author{
Lenis Aislinn C. Separa, ${ }^{1 *}$ Leonila J. Generales ${ }^{2} \&$ Ruby Jean S. Medina ${ }^{3}$ \\ *First author \\ Polytechnic University of the Philippines Research Management Office ${ }^{1}$ \\ Polytechnic University of the Philippines Bataan ${ }^{1,2,3}$ \\ (lacsepara@pup.edu.ph, ljgenerales@yahoo.com.ph, rjsiccion@yahoo.com) \\ Doi: https://doi.org/10.22452/jati.vol25no1.8
}

\begin{abstract}
The knowledge in the first language serves as the foundation of an individual in verbalising thoughts using the second language. The goal of language acquisition and language learning is one's ability to communicate effectively with other people in a situation that is ideal for a second language speaker. In cases where a communication situation is not suitable for the second language learner, verbal expressions oneself becomes problematic. This study investigates the contexts wherein second-language speakers of English find difficulty in the various communicative tasks they encounter when dealing with other people. It was asked from the university students in the Philippines to recount their experiences using English as a language of oral communication and to describe circumstances which made speaking difficult for them. Narrative accounts of their lived experiences were analysed through a qualitative thematic approach and developed the categories from emerging themes. Data reveals that emerging difficulties in English speaking not only involve lack of linguistic competence but also encompass psycho-social fears of speaking across different communication tasks. A proposed model for the context-based speaking difficulty includes (1) prowess in speaking; (2) pressure by time; (3) political power and control; and (4) people as of press.
\end{abstract}

Keywords: communication, speaking, speech, difficulty, English, English as a second language 


\section{Introduction}

The Philippine educational system requires English as a medium of instruction at all levels beginning Grade One. This policy aims to promote the proficiency of learners in using the English language, although out the years of schooling. It is expected from every student to learn the language and be able to use it in all other subjects in school, except in the subjects taught using the mother tongue. More importantly, English as a Second Language (ESL) learners must be able to communicate effectively elsewhere using the English language outside the classroom.

Although it is considered a second language in the Philippines, English is still not the usual language in relationship-building at home, in socialising in school, and even in transacting businesses in offices. The learning of the English language often stops in the four corners of the classroom since conversing in English in the country is often associated with formality and social status. The politics of this language is traceable in different aspects of speaking.

There is a notion that children who can afford to study in private and international schools are better English speakers than those who study in public schools. Similarly, people who speak English are considered to belong to the higher economic class in society and even perceived as more intelligent than those who cannot speak well. In cases when a person uses English, and everybody else speaks Filipino, other people may brand one as a social climber. English is considered as a 'special', rather than a 'second' language, that only those who know its rules of grammar and pronunciation are deemed worthy of using it. It appears that English gets treated as a language of the privileged few who were able to learn it from school or to acquire from communicating with other English-speaking individuals. This connotation created a barrier in embracing English as a language for everyone.

As this mindset continues to cultivate the perception of Filipinos towards the language, people tend to feel more inferior when encountering situations requiring them to speak in English. ESL learners become overly conscious with the sounds they produce, the appropriateness of vocabulary, the correctness of grammar, the perception of others, and even the mere presence of native speakers in conversations. All of these, and possibly a lot more, encapsulates the uncertainties Filipinos may experience when engaging with communicative tasks requiring English language.

Communicative competence is the emphasis on the ultimate goals of language teaching and learning. The ability of a person to talk with both native and non-native speakers of English indicates how well one can establish relationships and engage oneself to socialisation. The feeling of being 
understood creates an inclusive language environment that is fulfilling an individual's ability to understand other people. Conversely, the sense of selfdoubt and negative impressions from other people predisposes a person to question one's linguistic skills and often treated as a problematic situation to engage in communication with others.

\section{Problem Statement, Research Questions and Objectives}

Since speaking is an essential mode of communication for any ESL learner, this paper aims to know the different situations where it is expected from the university students to speak in English. This paper also intends to investigate how various elements involved in the communicative task predisposes them to face difficulties in speaking. As speakers of English as a second language, it is necessary to identify the sources of these difficulties to be able to integrate new teaching approaches in the academia that would address these situations that make Filipino ESL learners feel less confident in speaking.

\section{Literature Review and Theoretical Framework}

\section{Language Learning in Context}

In the General Theory of Second Language Learning, Spolsky (1988) pointed out an aspect of social context as influential in language learning through formal and informal situations. Formal situations include opportunities for language learning through institutionalised Education. In contrast, the informal situations pertain to social conditions which provide learners with venues for interacting with speakers of the target language.

In these contexts, ESL learners develop their competencies in speaking the language. In second language teaching and learning four communicative competencies should be developed, which includes grammatical competence, sociolinguistic competence, discourse competence, and strategic competence (Canale \& Swain, 1980). Though these are proposed bases for one's ability to use English in different contexts of meaning, this framework also provides a lead to the potential difficulties that learners may face during speaking tasks.

\section{Anxiety in Speaking}

The Affective Filter Hypothesis of Krashen, as cited in Norton (2000), proposes that affective filter consists of learner's motivation, self-confidence, and anxiety state - which refer to the individual itself, not to the social context. In Cagatay (2015), the speaking anxiety of Turkish EFL learners was investigated and 
resulted that Foreign Language Speaking Anxiety (FLSA) increases when speaking with native speakers.

Tupas (2002) introduced the concept of the culture of inferiority in the Philippines which makes learners feel that their knowledge and skills in English are not enough compared to the native speakers, thus making them feel insecure of their abilities in speaking. The feeling of inferiority creates a stressful disposition for a second language learner which may lead to anxiety. How they perceive the contexts of speaking can attribute to the ESL learners past experiences with similar situations. Pearson, Nelson, Titsworth, and Harter (2008) referred to this idea as perceptual constancy. A learner's initial perceptions and past experiences tend to become persistent and influence the current understanding.

Lo, Wong, Pang, Jin, and Chen (2018) found that the stress level of L2 speakers of English is the same in real and virtual situations of tests. Kelsen, (2019) has categorised The source of stress for speakers into four public speaking anxiety factors that are: (1) positive mindset; (2) physical symptoms; (3) preparation anxiety; and (4) performance anxiety. If the cause of the public speaking anxiety of students can be determined, it would be possible to create a more consistent pedagogical approach to the shaping of contexts in teaching that can build self-efficacy of students (LeFebvre, LeFebvre, \& Allen, 2018).

A study on Malaysian ESL learners revealed that those with low selfesteem, low motivation, and high apprehensions experience hardships in speaking skill though they have acceptable language skills (Leong \& Ahmadi, 2017). Nazir, Bashir, and Raja (2014) found among Pakistan ESL learners the awareness of the impacts of not being able to express oneself in English and even in committing errors during communicative tasks. This anxiety is often evident from the ESL learners when they have made an explanation in the classroom using the English language.

\section{Improvement of Oral Communication}

Verderber, Verderber, and Sellnow (2009) identified the public speaking effectiveness model, which suggests that the audience has a central role in the speech planning and speech making of an ESL learner. Along with the audience analysis, the speaking context, which includes physical setting, cultural setting, historical setting, and psychological setting affects how the audience perceives a speech. The perception of an ESL learner on the take of their audience on their oral communication competency becomes the contexts in which they may experience difficulties. Cavanagh, Leeds, and Peters (2019) studied 97 students of business majors and found that focusing on self-efficacy in teaching can improve 
oral communication skills of students which can be applied in professional settings later.

\section{Methodology}

\section{Research Design}

Having the objective of identifying the situations where speaking becomes difficult for the participants, this paper used qualitative research approach through a content analysis of the narrative accounts of the university students on how speaking in English becomes difficult for them in different situations.

\section{Procedures}

The Branch Ethics Board of the university provided clearance for conducting this study. Students accompanied the Informed Consent Form for data collection and have given the option to be excluded from the study; they are also aware that their responses would be used for research purposes only and would remain confidential.

Students answered the question: Narrate three situations wherein you had difficulty in speaking using the English language. Upon submission of the handwritten works of students, the responses were transcribed verbatim through manual coding. Data were then categorised using the qualitative thematic analysis to determine the emerging contexts of difficulties in speaking.

\section{Participants}

The participants in this study are $413^{\text {rd }}$ year students doingstudying a Bachelor of Secondary Education majoring in English at the Polytechnic University of the Philippines Bataan. These key informants were selected since they were studying a specialisation in teaching that focuses on their second language. Their narrations become the basis for generating themes and categories that describe their speaking difficulties.

\section{Results and Discussion}

\section{Fluency-based Difficulty}

Sentence construction plays a significant part in the difficulty of students when speaking. Considering that there are secondary schools requiring students to speak only in English during classes, students sometimes opt not to attend classes to avoid violating the rule that causes them to lose their self-confidence. A student reminisced: 
I didn't want to enter in her class because I don't want to speak even a single word. Aside from being so shy, I had a hard time in constructing a sentence, a phrase or even fragments whenever they asked me something about anything, even about the lesson discussed in the class. Neither because I don't have something to say nor I don't know what to say. I think I lose my confidence in speaking in front of the crowd, or even to the closest friends to whom I met during those times. [Rio]

Acquisition and learning of vocabulary in a specific language entail constant usage of words. Though English is considered the second language in the Philippines, still it is not used in the usual way of communication. Students start to feel shy about themselves for not fully understanding a question when another person uses unknown words during the conversation: "When I was an elementary student, I was so shy to answer most of the questions that my teacher gave me because by that time I only know few words of English and I am not yet to use it to communicate to others" [Dan].

During class presentations, learners can verbalise with ease the contents of the reference material, but explaining the contents based on one's understanding becomes a problem. Aside from unfamiliarity with some words, the limitation of a learner in expressing one's thoughts using English becomes a deterrent to describe concepts.

Of course, I know I mastered the topic before the day I report it, but the thought that I'm going to explain it to them is the difficult part. Because its explained in English language form, and I proudly admit that some explanation about that matter is hard for me to express especially in the English form. [Norbie]

As the inability to think of the right words to represent what they mean affects oral communication, the construction of statements that adheres to the conventions of grammar also becomes a problem. As an informant recounted,

...when the ISM students went to our school to visit us and me as one of the SSG officers I need to entertain them, and it was tough for me because I was so confused to my grammar if its right or wrong. [Christian]

Though some may value grammar when speaking, some can maintain their momentum in speaking despite subconsciously knowing their errors. 
...I couldn't stop myself from speaking; I can't even notice my grammar was not correct. For example, my capabilities are, because the situation moved me, and I got excited to finish my speech, my friends were laughing at me also my co-departments who noticed my wrong use of the word. [Lenard]

The reaction of other learners on the grammatical error committed by another learner suggest the value attributed to the correctness of sentence structure when speaking using the second language. Because of the mindset of learners of their limitations in vocabulary, they lose composure in speaking that lead to an inability to organise thoughts effectively. The situation becomes mindless speaking, which refers to not understanding the process and the output of speech entirely during the conversation.

One of my difficulties is also my hard time in here when expressing thought or idea in the form of English language. In first I'm going to feel nervous then every word I said is shaky and I don't know what I'm saying eventually. [Mariel]

I speak so fast that it makes me not to be aware of what I am speaking. While speaking, I spoke the word that is not suited to the sentence or I should say or wrong grammar wherein I spoke the adjective form of the word instead of the noun then my friend, Denver, shout[ed] "Politician!" With that, I laugh at myself for my stupidity. [Herlyn]

With the different scenarios involved in the difficulty in speaking based on the learners' vocabulary and grammar, second language learners experience a feeling of having disorganised thoughts together with the fear of committing mistakes.

As time goes by, I realised that it is harder to express yourself if you don't know what you are saying because you are getting confused and afraid to commit mistakes. [Arvey]

\section{Time-based Difficulty}

Since English is not the usual mode of oral communication of second language learners, the speed of constructing and verbalising thoughts also matters. When given a speaking task in school, the ability of the learner to think accordingly becomes weak when the time pressure is there. The referred speaking task is not merely a conversation, but a free speech. In one of the impromptu speech activities in class, a student narrated: 
...we began our impromptu speech. Sir Cris [not his real name] prepared a topic for each one of us. Sir Cris said, "next, no.5". That's my number, I thought. That time I felt nervous. I give you 30 seconds to think [Sir Cris] while setting the timer on his phone. Oh Lord Jesus, please help me. He said, Okay, Start. I do not know how to start my speech at that moment I speak, but while I was speaking, I did not correctly utter it. [Armando]

The mere knowledge that an activity is impromptu speaking gives learners negative anticipation of how they will perform. The nervousness that leads to mental block becomes the starting point of their pre-speaking preparations.

Sir John told us that we would have an impromptu speaking. That time I feel so shaky because of my nervousness. I don't know what I am saying regarding to the topic, bag, that I am going to give certain information. I want to give some more, but my mind says to stop because I cannot think well at the same time, my vocabulary is only limited. [Queen]

The grading system that linked to the speed of answer predisposes learners to focus on the obedience to the teacher's set rule rather than in composing a correct solution.

Sir Mark asked the class to speak in front. It is graded. I think it is and if you speak within 5 seconds your grade will be 5 , the topic I picked was about SIS, so I started one speech, but I was stuttering because of nervous and my mind goes empty and don't know what to say. [Anne]

Aside from the pressure experienced due to the limited time provided in preparing for the speech, the limited time allotted in the actual performance of a speaking task also becomes a problem. Some students may have a lot of things to say that may promote the development of their fluency may feel confined with the time specified to finish the speech.

We are asked to explain what our research all about is, and it should be done for only 15 minutes. Because of the time limit, I spoke fast and buckle because also I'm so nervous and thinking about what I should say because it is like impromptu speech. [Karl]

In addition to the impromptu speech, which causes learners to worry about the things to say for the new few minutes, questions that may just require 
brief and immediate answer also causes difficulty in speaking. The anxiety learners feel it adds to the inability to speak in English.

In addition to the impromptu speech that causes learners to worry about what to say for the first few minutes, questions which merely require brief response may also raise the difficulty in speaking.

Last sem, when we're discussing something, our teacher called me and asked me a question. I was very nervous at that time so I tell them that I don't know the answer. Surprise recitation always making me stutter so I didn't have any guts to an answer the given question. [Marianne]

The confidence level of ESL learners eventually goes down as they realise the pressure of arriving at a thought that they just to present. Though a question seems simple as they were able to start a speech, the anxiety they feel causes them to discontinue speaking.

When my name was called, I was so nervous. I picked the topic paper. At first, I was speaking good, but then I was so nervous and didn't say anything because of anxious, stopped and went to my chair. [Denver]

When this difficulty in speaking strikes suddenly, there are learners to recourse to injecting humour to the situation to save oneself from humiliation. The expression chaar is a filler used in speech to provide the audience with a signal that a person does not mean what is he just said and would like to treat it as a joke instead.

I explained it with my all effort and understanding, but honestly, my impromptu speaking became comedy. Why? Because I can't explain what I'm trying to express and had such informal words like [chaar]. [Rickalyn]

The time pressure brought by an impromptu question that requires an impromptu answer may have found to cause inconveniences to students when during speaking tasks, there are also ESL learners who manage to overcome the difficulty through focusing on the job rather than on the problems encountered.

...you will explain it on the spot. It was hard for me because I am not confident to speak in English specially in the front in our class...I immediately stand and go to the front of the class while my knees are shaking because of my nervousness. Shoes, that is your topic, my teacher 
said. And I started to speak even if I'm not sure if my grammar is correct. [Jester]

\section{Process-based Difficulty}

When learners are explaining a concept using the second language, they prepare for their presentations based on their planned flow of ideas. Once an unsolicited question from a listener intercepts the presentation, the learner experiences difficulty in answering the question.

I know my topic very well but it's just that I am so pressured and so eager to share my knowledge to my classmates. I had set the details in my mind but when she asked me question that I'm not prepared with there, I don't know how to continue and to end what I had started. [Acy]

Aside from the inability to answer on the spot questions from listeners, the learners also find it hard to continue with their presentations ahead. In some cases, they cannot even remember their presentation and cannot proceed with the speaking task.

When it is my turn to stand in front of class. I thought I knew everything about my report but when I'm continuously speaking in front of my teacher cut me and I was blocked out at that moment and when my teacher told me to continue my report I don't know what to do. [Wengekris]

Having a mental block is a common situation for ESL learners. Though the speaking task is for a religious gathering, the nervousness brought by the pressure of speaking in English adds to the tendency for this phenomenon. The idea of speaking alone in front of a team even to talk about praise and worship block mentally.

When I attended trainings in the church, I've experienced having mental block while I was in front of all the brothers and sisters. That time speaking in English is required and we are encouraged to speak one by one to utter our enjoyment toward the Lord. We were grouped in a team and in every session, the emcees were calling a team to share in front what we've enjoyed during session. When our team had been called, I became nervous and my heart was pumping so fast to the extent that I was mental blocked. [Grace]

Another apparent reason for experiencing mental block is teacher's testing of knowledge of students in an impromptu and oral manner. The 
unwanted feeling of being asked of new knowledge, as well as the fear of the teacher getting mad, adds to the tendency of forgetting to go through one's answer.

When my teacher asked me about my report, that time my report is about idiomatic expression. I delivered my report well but when my teacher gave me another sets of idioms I cannot give the meaning of them. Then I experience mental block that time I am afraid that my teacher will get mad at me I had the idea but I am afraid to share it because maybe it is wrong. [Prexy]

\section{Status-based Difficulty}

ESL learners also face difficulty in terms of communicating with other people that do not belong to their same age group and nationality. Speaking with someone in school or to a foreigner who is a native speaker of English, contributes to the non-assertiveness of learners.

\section{Fear of Superior}

In the previous discussion, learners pointed out the impromptu questions their teachers ask them that makes them stutter or experience mental block. Students haven't specified in their accounts, but it seems that knowledge of the authority and teacher's position might have affected this. Similarly, their experiences in speaking with the highest official of the school indicate a difficulty with assertiveness. Though learners know how to answer the question, they become conscious of the correctness of grammar when communicating with people in position.

When I was in high school, we need to talk in our principal, because they have a foundation week...And when all the officers are in the principal office, some of my classmates feel nervous because we need to talk in English...I feel nervous, and I don't know what is the first thing to do because I am actually afraid to speak a second language. And when I start to speak, I feel I have many mistakes when I speak in English. Ma'am P asked another question about what design they can do in our stage and I can't speak for the second time because I am afraid in our principal. [Christian]

A speaking situation like an interview creates an environment that requires a learner to answer correctly and in a formal way. The pressure felt results to nervousness in answering even a practical question evidenced by a stuttering speech and rolling eyes during the conversation. 
Way back 2015, when we were being interviewed by the school dean, she asked me what course I am going to take and why did I choose it. I didn't give her a straight answer so I roamed my eyes inside her office. While looking around, I felt very nervous. I get a chance to answer her question when she repeated the question. So I calm myself and answer her question stutteringly. [Crizia]

Even in social events where authority in school becomes part of the jury for a speaking task, the ESL learner feels the pressure of doing well in speaking, especially in the aspect of grammar usage. The familiarity of the expectation of a remarkable person for a learner prompts them to be more careful in speaking.

It was a pageant night when we're all candidates are on the question and answer portion; it took a great courage to spit every word using the second language in front of the audience with your professor as your judge. I must be careful with my words and grammar since I am the representative of our section. [Rio]

\section{Fear of Foreigners}

The presence of native speakers of English makes ESL learners less confident in speaking the language. Though the learner standing was a teacher in a high school class and was considered the person in authority in class, the fear of reprimanding the student using the English language happens.

The time that I was observed at Sunny Hillside School, I have a student that cannot speak Tagalog and only English language. It is hard for me to control the way she act in the classroom because I'm afraid to talk with her. [Rachel]

The feeling of inferiority of being a non-native speaker intervenes in an ESL learner despite the function, or the status one has in a communication setup. Take the role of an English teacher to a student that speaks English as the first language makes one unsure of own communicative competence.

Another learner experienced a casual question from a native speaker in an informal communication situation. Though the question seems simple for the learner, the mere knowledge that the person is a foreigner makes one experiences lapses in constructing an answer.

...this guy with his friends and he approached Karla saying,"Did you know where the caretaker is?" ... I was thinking that he was just some 
English-speaking tourist who happened to be visiting the resort...and suddenly Karla passed the question to me and I was like processing ...processing...process uh..uh.. "They're inside.. That was the phrase that came from my mouth. [Laiza]

\section{Expectation-based Difficulty}

\section{Social Pressure}

Filipino is the first language in the country. Since ESL learners are getting training to speak in English, it is expected as the primary language against the classroom policy in a formal communicative task in school like oral presentations. Because the learner is not allowed to speak his first language, he admits that he is not confident to report in class.

...I got mental blocked because of pressure since I was the first one to report in front of the class and I'm not allowed to speak in Filipino. Maybe the reason why I couldn't express myself in English that time is because I'm lacking of self-confidence which is very important when you're speaking in the language. The end result, I just read what's written in the book and violate the rule of not speaking in Filipino. [Jessa]

Being an ESL learner who takes English as a major track in pursuing a baccalaureate degree in Education creates a mindset for acquaintances that one is fluent in speaking the language. Aside from this expectation from a college student, the background of the other person being a teacher adds to the anxiety of expressing oneself with the fear of being judged negatively for having grammatical slips.

Recently, when I work at the Eastcam Tect. Corp. one of my co-worker is a former teacher in her province. When she found out that I am taking the course of education major in English she started to talk to me in English. She always started the conversation with me through English language. At first, I feel pressured because she is a former teacher. She is able to know if my grammar is correct or not. [Jadeverly]

If the feeling of being gauged based on speaking competency causes discomfort, the pressure of practising in public what one should know about English may be considered even more humiliating for a learner.

I've been the translator of the Chinese sister... In the first day of staying there, I admitted to my teammates that I was not fluent in speaking 
English even though I am taking up Bachelor of Secondary Education Major in English. I just told them that everything could be learned...so, they told that I should learn from doing... They assigned me to the task I never imagined. I became the translator of one of the sisters. The battle started and the struggle is real at first I didn't know how to approach that sister. I didn't even know how to start the conversation. [Leann]

The expectation for being a good English speaker is not only seen in the type of program enrolled to but also associated with the homogenous class a learner belongs. A person who is excelling in school also expected to be a fluent speaker. An ESL learner remembers how a previous teacher made her feel that way:

I remember in my high school days. There is a teacher mandated us to speak in English anytime we are inside the school premises. Then one time when she is discussing, she asked me about something then she command me to answer her in English while in the first place she construct her question in Tagalog language. I try to speak in English but while speaking I paused. Then my teacher said that "why you stop" I said that "I feel like I'm lacking English words ma'am" then she said that, "ano ba naman leslie, nasa highest section ka oh! Sana naman panindigan mo! [Oh my Leslie! You are in the highest section. You must prove it]. [Leslie]

Since English is not the everyday language in casual conversations in the Philippines, highly regarded are those who are fluent in using it. But there are times when the admiration one receives for being an English major becomes an opportunity for ridicule that leads to a person's loss of composure.

A friend of my cousin who was not seen by us for months gave a visit and asked, what am I taking up...My cousin proudly said "Education English major yan!" and her friend looked at me and said "Sample! Sample!" and I was like...'hahahahaha'. I felt like my feet are pinned into the ground and I can't move. Where is my dignity, my poor dignity. I asked myself in my mind. [Kimberly]

Aside from the direct association with mockery, the expectations set on a learner who studies English may even translate to an undesirable situation of being assessed for one's language abilities. A conversation which happens not for communicative purpose but proficiency testing is considered an adverse situation. 
I'm on my part time job during that time and this professor knew that I'm taking Education and an English major so he said that he will test my English skill. I smiled at him and I said that I'll try my best. He throws questions at first then he said I should ask him too and try to have a normal conversation with him still speaking in English. [Michelle]

As an ESL learner exerts effort to perform social functions using the English language while others explicitly show how fluent they are in speaking makes a learner realise more what s/he cannot do.

When I am teaching in our church and there are a few words that I translate it in English. My churchmates were shouting wow! English. Then they will talk in English too. And it is hard for me because they can talk pure English. [Mariel]

\section{Social Insecurity}

When an ESL learner encounter people who can speak in English better than they do, insecurities set in. The idea that one is not that competent in oral communication compared with others decreases a learner self-confidence. When this happens, mental block and stuttering happen. One learner recounts an experience on this.

...Everyone is speaking in English and they are using it every moment of conversation. Maybe, I guess I am the only one who was not speaking because I am really shy to communicate with them. I felt like I was an outcast because I'm not able to use it in conversation. And then I got called by the speaker. I was stunned and got intimidated. In the end, I don't finish my answer I ended up stuck and frozen. [Leizeil]

Nervousness also gets in the way during a speaking task in school, especially at times when the ESL learner compares oneself with the classmates. The perception of the competency of others causes a learner to have doubts about his own's competency.

I'm so nervous because many of my classmates are very good when speaking in English, I will say that I can speak English but when I'm nervous it takes me down. So back to the story, until my name was called I'm still so nervous, even I'm in front reciting I started to spoke stuttering because of nervousness. [Karl] 


\section{Crowd-based Difficulty}

\section{Fear of People}

In the previous discussion, fear originates from the insecurity with the perceived English competencies of other people. But even without the impression on others' competencies, ESL learners still experience difficulty. This time, being with a crowd that is unfamiliar to a learner affects their composure in speaking.

Back in high school, it's the first time for me to encounter a situation which I had trouble speaking the second language, when we competed for the Division School Press Conference... when we are interviewed one by one about our background in Broadcasting. Since we're all in one event with different schools and different students, I'm a bit nervous and shaky to speak in front of the big crowd just to answer a simple question by the speaker. [Anne]

This dilemma of nervousness in front of people is also evident in the nonverbal cues of a learner. When one has a mindset that public speaking even to a familiar crowd is an undesirable situation, learners tend to develop this habit of not initiating the necessary physical moves in speaking.

...The teacher would give us a piece to be delivered two to three weeks before the actual performance. I remember memorising every piece given to us but when the actual day came, I can't even stand up from my seat because I was scared of speaking in front of people. [Denver]

Stage fright appears to be the problem when speaking for a crowd. Though the listeners are known to the ESL learner, they develop the thought that the situation in which people look at him while speaking makes him less confident in speaking. The act of standing itself contributes to this discomfort in speaking and returning to one's seat regains the composure of a learner.

The second me is whenever I am going to speak in front of the class (so, this usually happens) the thing is I am not going to speak in front of the class I feel uneasy. It's like there's something watching me and I can't keep my hands on sweating and I usually stutter and can't think of the right words to say but when I get back to seat, I thought I should've said that. [Roianne]

An ESL learner may also lose confidence in speaking with just imagining how it is like to talk in front of others. The mere thought of the presence of a 
crowd makes an ESL apprehensive of a specific communicative task even though learner knows it well.

Last school year, one of our professors gave us a task. I know that is easy for me to do what our professor said because it is not new for me to hear that task and it is to report in front of classmates and her. I don't know why I am being paranoid every day, when it comes to my mind that soon I will be the next who will teach or report in front of many people. [Justine]

\section{Fear of Humiliation}

Being asked of something that an ESL learner is unsure of initiates the feeling of being humiliated with other people. The fear of being rejected by the crowd also passes one's thoughts if questions asked were not correctly answered in the classroom set-up.

...It was very humiliating, the thing that you know what you were going to say but you can't because you were to scared that you might be wrong. I'm too scared in rejection. My teacher just asked why I need to discuss again about that structure of sentence when it's already discussed... I get too nervous and I stutter that's why I didn't answer it correctly. [Rachelle]

The act of stuttering is considered a humiliation for an ESL learner. There is an anticipation that not being able to speak fluently would give classmates a chance to laugh at the person. One learner has shared her thoughts in this way.

...When I heard that there's a lot of words coming up in my mind, I said to myself what if my classmates laughed at me? What if I stutter in front of them? I see my classmates confidently speaking in English. I was nervous my hands are sweating. As Sir __ called my name, my confidence went down only I can hear is the fast beat of my heart. I stutterly speak and I don't know if the words are perfectly connected to others. [Le-Shaidda]

Aside from stuttering, ESL learners believe that problems in the subjectverb agreement are also a ground for being laughed at by classmates. This mindset causes them to be extra cautious with what they say and tends to inhibit them from speaking spontaneously. 
I still remember the time when I was called by my English teacher in High School in one of our discussions unarmed with the words I needed cause my vocabulary that time is just limited. I can't express myself to speak because of the fear that I might get laughed by my "grammarian" classmates. I felt embarrass on myself unable to speak the language in a fluent manner that time. [Jessa]

Since oral communication involves the auditory sense, ESL learners also experience inferiority due to the production of non-conventional speech sounds. If a person has not a common way of pronouncing words, there are times when they are about to be bullied. The act of mimicking the manner of one's speaking signals a negative impression to the learner.

I had this improper way of saying the letter " $r$ ". I noticed it every time am assigned to react a story. Everytime, I am assigned to read a story. Everytime I say a word with letter " $r$ " I always think what will my classmates says about my speaking. I often think that they would thought about me as a conyo. Because one time, I encounter someone who mimic how I say such as a word and I feel insulted about that someone who mimic my way of speaking. [Anne]

ESL learners, being students who take English as the major field of study, expects themselves to be fluent speakers of the language. When one fails to perform according to their self-expectation, they also develop the fear of being criticised by other people.

First of all I hate English speaking in English I don't know why I have but already here. First of my unforgettable moment when I'm in first year. Of course we are English major we must speaking in English in introduction. I'm afraid that my classmate will criticise me the way I introduced myself even in class recitation I know the answer but I don't know how to answer it in English language. I don't have enough confidence to be trying hard in front of others. [Armando]

Classmates who bully ESL learners are leading potential source of criticism. The act of copying the manner of speaking of someone is a display of disrespect to another learner. When one encounters this situation of being mimicked, confidence in speaking goes down. As the ESL learner recalls this undesirable situation, she becomes anxious to assert oneself subsequently. 
...she noticed me and call my surname to answer. I stand up and confidently say the answer in the class. But as I talk to the class, I hear someone is mimicking my voice...So my confidence became lower and I immediately sit down pretending that I am done talking. Since then, every time we had a recitation, I don't have enough confidence to raise my hand and recite in the class. [Mariel]

Aside from mimicking as a reason for losing confidence in speaking, an ESL learner shared how other learners humiliate a speaker through not only making them a laughingstock. Labelling them for committing errors in speech seems to appear as a part of the worse scenario. Such experience makes an ESL learner develop the difficulty in boosting one's confidence in speaking.

...Another reason was that most of my classmates kept on criticising the ones who are speaking in front. Whenever you have said something wrong, they will laugh at you and keep laughing and eventually they will give you a nickname on the funny thing that you said/told. I think today there's still that fear hidden inside of me, I don't know what to do and how could I overcome it. [Elsie]

\section{Conclusion}

Learning a second language is said to be based on the first language. That by having a solid foundation of the first language makes a competent speaker of the second language. It also found to be dependent on the speaking situation learner experiences. The 4Ps of anxiety introduced by Kelsen (2019) describes the sources of stress of a person in public speaking may not always be present in the context of language learning of Filipino college students.

The difficulty of ESL experienced with fluency involves being not used to using the language in every day, thereby limiting the necessary vocabulary set and naturalness of grammar coherence. Time plays a significant role in their speaking difficulties as their confidence goes down as they feel the pressure of the need for impromptu speaking, and as they become too worried about questions that need immediate answers.

Aside from fluency and time, ESL learners become less confident in speaking tasks that are interrupted, which require them a sudden change in the flow of thought and even lead to a mental block. Even the social status of the person whom they converse with becomes a barrier to fluency. ESL learners feel as being assessed and judged based on their speaking abilities when talking with people who hold a designation in school. Also, native speakers of English make 
them doubt their capacity to speak in English with the mere presence of foreigners.

The expectation of the society of being good communicators contributes to the pressure they feel as ESL learners. The alleged prohibition of using the first language that may include code-switching, in English class makes it even harder for them to process thoughts. As they encounter other English speakers that seem to be more fluent than them, ESL learners tend to feel inferior, and nervousness gets in the way. Since they do not want to be humiliated and criticised for how they communicate orally, ESL formed the mindset for not wanting to engage in public speaking.

Based on the synthesis of the data themes, the context-based difficulties on oral communication of Filipino college students can be categorised into (1) fluency, (2) time, (3) process, (4) expectation, (5) status, and (6) crowd. As these difficulties may be present in the 4Ps of Anxiety of Kelsen (2019), a new set of categories can be derived from the experiences of ESL learners. The proposed 4Ps of Context-Based Difficulty Model on Oral Communication consists of (1) prowess in speaking; (2) pressure by time; (3) political power and control; and (4) people as press.

As these difficulties surface in the experiences of ESL learners in the Philippines, educational institutions may consider adapting language learning approaches that would lessen these challenges, and that would make English a usual tool for communication, rather than a gauge of one's competency.

\section{Acknowledgements}

We would like to thank the students who entrusted sharing their experiences as informants in writing for this article. Acknowledgements are also extended to the Polytechnic University of the Philippines Research Management Office and Bataan Branch for supporting us in this endeavour.

\section{References}

Canale, M., \& Swain, M. (1980). Theoretical Bases of Communicative Approaches to Second Language Teaching and Testing. Applied Linguistics, I(1), 1-47. doi:10.1093/applin/i.1.1

Cavanagh, T. M., Leeds, C., \& Peters, J. M. (2019). Increasing Oral Communication Self-Efficacy Improves Oral Communication and General Academic Performance. Business and Professional Communication Quarterly, 82(4), 440-457. doi:10.1177/2329490619853242 
Kelsen, B. A. (2019). Exploring Public Speaking Anxiety and Personal Disposition in EFL Presentations. Learning and Individual Differences, 73, 92-101.

Leong, L., \& Ahmadi, S. M. (2017, March 20). An Analysis of Factors Influencing Learners' English Speaking Skill. International Journal of Research in English Education, 34-41.

LeFebvre, L., LeFebvre, L., \& Allen, M. (2018). Training the Butterflies to Fly Information: Cataloguing Student Fears About Public Speaking. Journal of Communication Education, 67(3), 348-362.

Lo, E., Wong, A., Pang, J., Jin, X., \& Chen, S. (2018). Effects of Stress on Second Language Speech Performance in Real and Virtual Public Speaking Environments. In C. Speelman, \& D. Chhabra (Eds.), Conference Proceedings: $7^{\text {th }}$ Annual International Conference on Cognitive and Behavioral Psychology (CBP 2018) (pp. 2-11). Singapore: Global Science and Technology Forum.

Nazir, M., Bashir, S., \& Raja, Z. B. (2014). A Study of Second Language SpeakingAnxiety among ESL Intermediate Pakistani Learners. International Journal of English and Education, 3(3), 216-229.

Norton, B. (2000). Identity and Language Learning: Gender, Ethnicity, and Educational Change. Harlow: Pearson Education Limited.

Pearson, J., Nelson, P., Titsworth, S., \& Harter, L. (2008). Human Communication. New York: McGraw-Hill.

Spolsky, B. (1988). Bridging the Gap: A General Theory of Second Language Learning. TESOL Quarterly, 22(3), 377-396. doi: 10.2307/3587285

Tupas, T. R. (2002). Second Language Teaching. Philippines: UP Open University. Verderber, R. F., Verderber, K. S., \& Sellnow, D. D. (2009). Effective Speaking: Challenges and Solutions. Singapore: Cengage Learning Asia Pte. Ltd.

\section{List of Informants}

1. Leslie Aragon (Bachelor of Science in Education major in English, Polytechnic University of the Philippines Bataan)

2. Queen Adela Arrieta (details: Major, Schoo, University) (Bachelor of Science in Education major in English, Polytechnic University of the Philippines Bataan)

3. Anne Shierly Biligan (details: Major, Schoo, University) (Bachelor of Science in Education major in English, Polytechnic University of the Philippines Bataan) 
4. Kimberly Bosquillos (details: Major, Schoo, University) (Bachelor of Science in Education major in English, Polytechnic University of the Philippines Bataan)

5. Karl Louie Cabatuan (details: Major, Schoo, University) (Bachelor of Science in Education major in English, Polytechnic University of the Philippines Bataan)

6. Leann Calpo (details: Major, Schoo, University) (Bachelor of Science in Education major in English, Polytechnic University of the Philippines Bataan)

7. Crizia May Cepe (details: Major, Schoo, University) (Bachelor of Science in Education major in English, Polytechnic University of the Philippines Bataan)

8. Le-Shaidda Culanag (details: Major, Schoo, University) (Bachelor of Science in Education major in English, Polytechnic University of the Philippines Bataan)

9. Leizeil Del Rosario (details: Major, Schoo, University) (Bachelor of Science in Education major in English, Polytechnic University of the Philippines Bataan)

10. Prexy Grace Demaisip (details: Major, Schoo, University) (Bachelor of Science in Education major in English, Polytechnic University of the Philippines Bataan)

11. Michelle Dimaculangan (details: Major, Schoo, University)

12. Dan Carl Divina (details: Major, Schoo, University) (Bachelor of Science in Education major in English, Polytechnic University of the Philippines Bataan)

13. Rachelle Eco Cruz (details: Major, Schoo, University) (Bachelor of Science in Education major in English, Polytechnic University of the Philippines Bataan)

14. Herlyn Escuyos (details: Major, Schoo, University) (Bachelor of Science in Education major in English, Polytechnic University of the Philippines Bataan)

15. Justine Jude Guiang (details: Major, Schoo, University) (Bachelor of Science in Education major in English, Polytechnic University of the Philippines Bataan)

16. Grace Lyn Guillermo (details: Major, Schoo, University) (Bachelor of Science in Education major in English, Polytechnic University of the Philippines Bataan) 
17. Mariel Jalova (details: Major, Schoo, University) (Bachelor of Science in Education major in English, Polytechnic University of the Philippines Bataan)

18. Wengekris Laurita (details: Major, Schoo, University) (Bachelor of Science in Education major in English, Polytechnic University of the Philippines Bataan)

19. Jadeverly Anne Lipata (details: Major, Schoo, University) (Bachelor of Science in Education major in English, Polytechnic University of the Philippines Bataan)

20. Acy Ann Marullo (details: Major, Schoo, University) (Bachelor of Science in Education major in English, Polytechnic University of the Philippines Bataan)

21. Christian Matias (details: Major, Schoo, University) (Bachelor of Science in Education major in English, Polytechnic University of the Philippines Bataan)

22. Christian Milla (details: Major, Schoo, University) (Bachelor of Science in Education major in English, Polytechnic University of the Philippines Bataan)

23. Rickalyn Monzaga (details: Major, Schoo, University) (Bachelor of Science in Education major in English, Polytechnic University of the Philippines Bataan)

24. Norbie Joy Nazar (details: Major, Schoo, University) (Bachelor of Science in Education major in English, Polytechnic University of the Philippines Bataan)

25. Arvey Leo Olivera (details: Major, Schoo, University) (Bachelor of Science in Education major in English, Polytechnic University of the Philippines Bataan)

26. Denver Onggos (details: Major, Schoo, University) (Bachelor of Science in Education major in English, Polytechnic University of the Philippines Bataan)

27. Roianne Ora (details: Major, Schoo, University) (Bachelor of Science in Education major in English, Polytechnic University of the Philippines Bataan)

28. Jester Ponpon (details: Major, Schoo, University) (Bachelor of Science in Education major in English, Polytechnic University of the Philippines Bataan)

29. Lenard Pullido (details: Major, Schoo, University) (Bachelor of Science in Education major in English, Polytechnic University of the Philippines Bataan) 
30. Marianne Ramirez (details: Major, Schoo, University) (Bachelor of Science in Education major in English, Polytechnic University of the Philippines Bataan)

31. Jessa Salazar (details: Major, Schoo, University) (Bachelor of Science in Education major in English, Polytechnic University of the Philippines Bataan)

32. Armando Santiago Jr. (details: Major, Schoo, University) (Bachelor of Science in Education major in English, Polytechnic University of the Philippines Bataan)

33. Laiza Mae Silva (details: Major, Schoo, University) (Bachelor of Science in Education major in English, Polytechnic University of the Philippines Bataan)

34. Elsie Vibora (details: Major, Schoo, University) (Bachelor of Science in Education major in English, Polytechnic University of the Philippines Bataan)

35. Rio Liezel Yambao (details: Major, Schoo, University) (Bachelor of Science in Education major in English, Polytechnic University of the Philippines Bataan)

Date Received: 5 January 2020 Date of Acceptance: 1 June 2020 